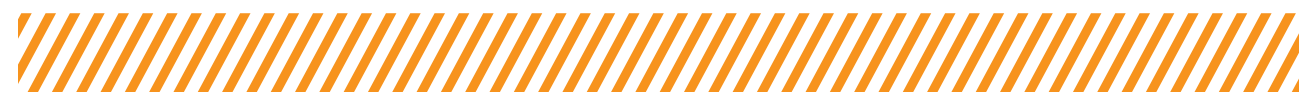

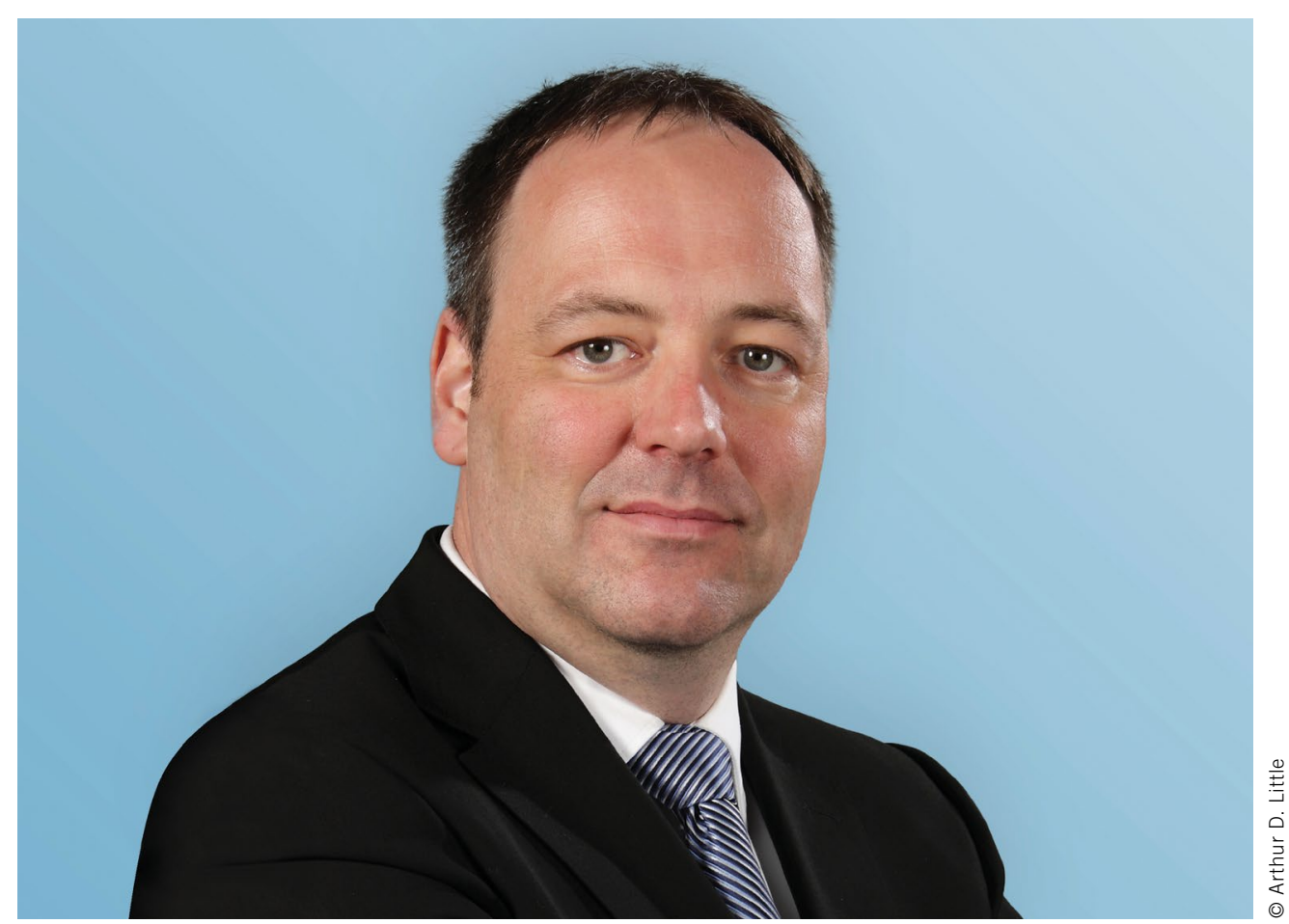

Klaus Schmitz

Partner bei Arthur D. Little

\section{Einstieg der Tech-Giganten}

Mit Apple verbunden werden bahnbrechende Innovationen, neue Geschäftsmodelle, herausragendes Design, intuitive Bedienung und viel Prestige. Der Mythos beruht besonders auf dem iPhone, das gleich mehrere Branchen umkrempelte und Big Player zu Fall brachte. Es verwundert daher wenig, dass das Konzept eines Apple Car seit Jahren für Aufregung sorgt und die Fantasien beflügelt. Beim Einstieg von Apple und anderen Tech-Giganten in die Mobilität geht es um nichts weniger als um die dominierende Stellung im Ökosystem. Die Automobilbranche wurde lange von wenigen OEMs dominiert, die eine Vielzahl von Zulieferern orchestrierten. Diese Ära neigt sich dem Ende entgegen. Das automobile Ökosystem entsteht neu, die Elemente sind bereits sichtbar: Das klassische System wird ergänzt um Software und Services sowie um Zulieferungen für autonomes und elektrisches Fahren - der Verbrenner verschwindet langfristig. Von besonderer Bedeutung ist dabei der Zugang zum Endkunden und die Beherrschung disruptiver Technologien im Antriebsstrang und bei Automatisierung sowie Digitalisierung. Apple und auch Alphabet sind dabei in der besonderen Situation, dass sie den Zugang zum Endkunden und seinen Daten bereits besitzen, wenn auch in einem anderen Umfeld. Die entscheidende Frage ist daher, welche Rolle beziehungsweise welches Geschäftsmodell im neuen Ökosystem angestrebt wird. Dies könnte für Alphabet ein ganzes Stück klarer und einfacher zu beantworten sein, da die ausgeprägte Stärke beim Deep Learning, das bestehende Geschäftsmodell und die sichtbare Positionierung von Waymo auf eine Stellung als reiner Softwareplayer hindeuten. Apples bisheriges Profil hingegen deutet eher in Richtung eines OEM: Die Stärken lauten hier Design, Beherrschung des Ökosystems und die Integration technischer Innovation. Doch für einen durchschlagenden Erfolg beim Aufbau einer Automarke Apple wird es nicht reichen, eine fortschrittliche Batterie oder ein schickes Infotainment-Interface aufzubauen. Das Publikum erwartet eine holistische Revolution des Fahrens, des Erlebnisses eines Fahrzeugs und der Mobilität. Die in viele Richtungen zeigenden Gerüchte rund um das Apple Car legen hier die Komplexität des Projekts offen und stehen stellvertretend für das Ringen der gesamten Industrie um den richtigen Weg nach vorne.

So scheint bis dato ungeklärt, ob Apple auf der Suche nach einem Auftragsfertiger wie beim iPhone ist oder wie Tesla eigene Produktionskapazitäten aufbauen möchte. Ähnliche Fragestellungen ergeben sich bei Fahrzeugbasis und Antriebskomponenten: Forciert man eine Badge-Lösung und wertet ein weitgehend existierendes Fahrzeug zum Apple-Fahrzeug auf, oder sieht man darin die Basis für eigene Weiterentwicklungen? Apple steht an ähnlichen Scheidewegen wie die OEMs. Am Spagat zwischen Hardware, Softwarekompetenz und den hohen Erwartungen an neue Mobilitätsservices wird sich auch der Riese aus Cupertino messen lassen müssen. 